\title{
INTENSITY OF NITRIC OXIDE SYNTHESIS IN THE BLOOD OF RATS UNDER THE INFLUENCE OF SODIUM FLUORIDE
}

\section{Kolisnyk I.L}

Kharkiv Medical Academy of Postgraduate Education

\begin{abstract}
The influence of fluoride ion as a chemical agent affects the metabolism, the change of which is manifested in functional and structural changes. The final stable metabolites of $\mathrm{NO}$ include nitrite and nitrate anions $\left(\mathrm{NO}_{2}, \mathrm{NO}_{3}\right)$, the concentration of which serves as an indirect method for estimating the intensity of NO synthesis. The concentration of NO is a major factor in its numerical biological effects (regulatory, protective). At low NO concentrations, direct effects aimed at maintaining homeostasis, such as the vascular, respiratory, and nervous systems, predominate; at high concentrations of NO, indirect effects prevail, due primarily to the formation of peroxynitrite. It is known that when the rate of free radical reactions in the body increases, NO can react with a superoxide anion radical to form peroxynitrite, a highly reactive compound with destructive properties against proteins and lipids. Oral administration of FN to rats in doses of $1 / 10$ and 1/100 DL50 leads to an increase in the content of nitrite and nitrate anions in the blood plasma during the first 30 days, which indirectly indicates excess production of nitric oxide, which in the initial stages of intoxication may play a compensatory role, but subsequently cause pathological reactions associated with the activation of oxidative stress. The decrease in nitrite and nitrate anions at the end of long-term action of FN indirectly indicates a decrease in nitric oxide generation, which may be associated, in particular, with an increase in peroxynitrite concentration due to the use of nitric oxide in reaction with superoxide anion radical and antioxidant deficiency.
\end{abstract}

Key words: sodium fluoride, nitric oxide, intoxication, nitrite anions, nitrate anions

\section{Introduction}

Fluorine compounds are widespread in nature and are an industrial pollutant [1]. In the free state, fluorine does not exist in nature, but forms inorganic and organic complex compounds - fluorides, whose content in the Earth's crust is approximately $0.06-0.09 \%$. It is known that low concentrations of fluoride are necessary for the normal growth and development of the organism. However, with excessive intake of the body, there are significant disruptions of vital organs, cell damage, necrosis [2]. The influence of fluoride ion as a chemical agent affects the metabolism, the change of which is manifested in functional and structural changes. At the level of damaging factors, there are several pathogenetic mechanisms, namely: disruption of energy supply to processes occurring in the cell and damage to membrane structures and enzyme systems of the cell [2]. Sodium fluoride (FN) is a metabolic poison, and it primarily has a membrane damaging effect. At chronic chemical loading, there are system changes of a functional condition of the organism at all levels of integration, or the syndrome of ecologically caused reduction of the body's resistance. The result of the development of this syndrome is the effect of chemical modification, i.e., an increase in the number and deterioration of diseases of certain organs against the background of reduced immune parameters and impaired protective and adaptive capabilities [3]. With increasing amounts of sodium fluoride in the body, diseases of the CNS, endocrine system, and digestive organs, including the liver, develop. The experiment found that in prolonged exposure to sodium fluoride, protein and fatty dystrophy is diagnosed in the liver, as well as the appearance of lipid peroxidation products in the blood [3]. The degree of pathogenic influence in the development of a stress response is largely determined by the state of stress-limiting systems, in particular, the nitric oxide (NO) system. It is proved that NO-dependent regulation of the central parts of the stress response is provided by the fact that the pituitary gland receives from the hypothalamus a widely represented NO-ergic innervation [4]. The identified property of NO to modulate the release of major pituitary stress hormones suggests an important role of NO in the regulation of its functioning and prevention of excessive activation of the central part of the stress system. There are data in the literature on the ability of NO to block the peripheral release of stress hormones and protect cells and organs from stress damage [5]. In particular, at low concentrations NO inhibits the release of catecholamines from the adrenal glands and sympathetic nerve endings, leading to a limitation of the stress response [3].

The final stable metabolites of $\mathrm{NO}$ include nitrite and nitrate anions $\left(\mathrm{NO}_{2}, \mathrm{NO}_{3}\right)$, the concentration of which serves as an indirect method for estimating the intensity of NO synthesis [6]. The concentration of NO is a major factor in its numerical biological effects (regulatory, protective). At low NO concentrations, direct effects aimed at maintaining homeostasis, such as the vascular, respiratory, and nervous systems, predominate; at high concentrations of NO, indirect effects prevail, due primarily to the formation of peroxynitrite. It is known that when the rate of free radical reactions in the body increases, NO can react with the superoxide anion radical to form peroxynitrite, a highly reactive compound with destructive properties in relation to proteins and lipids [7].

The aim of the research was to determine the intensity of nitnic oxide synthesis under conditions of prolonged fluoride intoxication.

\section{Material and methods}

The studies were performed on mature Wistar

\footnotetext{
${ }^{*}$ To cite this English version: Kolisnyk I.L. Intensities of nitric oxide synthesis in the blood of rats under the influence of sodium fluoride. //
} The Medical and ecological problems. - 2020. - Vol 24, № 5-6. - P. 25-28. 
rats weighing $180-220 \mathrm{~g}$, which were kept in a stationary vivarium at a constant temperature and natural light in plastic cages on a balanced diet. Rats were orally inoculated with the probe with aqueous solutions of sodium fluoride once daily for 60 days in doses of 1/10, 1/100 and $1 / 1000 \mathrm{DL}_{50}$, which were $20 \mathrm{mg} / \mathrm{kg}, 2 \mathrm{mg} / \mathrm{kg}$ and $0.2 \mathrm{mg} / \mathrm{kg}$ of body weight (average lethal dose of sodium fluoride for rats, obtained orally, is $200 \mathrm{mg} / \mathrm{kg}$ ). All procedures were performed under standard conditions from 9:00 to 10:00, the animals were excluded from the experiments 24 hours after the last administration of sodium fluoride. The control animals were injected with appropriate volumes of drinking water. The study was performed on the 10th, 20th, 30th, 50th and 60th day after the launch of the experiment. There were 10 animals in each group. Animals were euthanized by decapitation with a guillotine knife, pre-anesthetized with sodium thiopental at a dose of $50 \mathrm{mg} / \mathrm{kg}$ body weight. The liver was perfused with the cooled solution until the complete removal of traces of blood, extracted, cut out areas of connective tissue, dried on filter paper, frozen and stored in liquid nitrogen. To obtain liver homogenate, a sample of tissue was ground in the cold and homogenized in a glass Potter homogenizer with a Teflon pestle in a cooled isolation medium $(0.25 \mathrm{M}$ sucrose solution, which was prepared in $0.01 \mathrm{M}$ Tris- $\mathrm{HCl}$ buffer, $\mathrm{pH}-7.4$ with the addition of 1 mM EDTA). When working with animals, we were guided by the requirements of the
"European Convention for the Protection of Vertebrate Animals Used in Experiment and Other Scientific Purposes" (Strasbourg, 1986), the Law of Ukraine №3447-IV as of 21.02.2006 "On the Protection of Animals from Cruel Treatment".

The intensity of NO synthesis in rats under conditions of prolonged fluoride intoxication was determined by the content in the blood plasma of its final stable metabolites - nitrite and nitrate anions (reflect the total response of all isoforms of NO synthase). The content of nitrite and nitrate anions in blood plasma was determined spectrophotometrically at $540 \mathrm{~nm}$ by color reaction with Griss reagent. Before the start of the analysis, protein precipitation of $0.5 \mathrm{n} \mathrm{KOH}$ and $5 \% \mathrm{ZnSO}$ was conducted. Since the diazotization reaction is specific only for nitrites, their previous reduction was performed to determine nitrates. Statistical methods were used for data processing.

\section{Results and discution}

The rats infected with $\mathrm{FN}$ at a dose of 1/10 DL50 demonstrated a significant $(p<0.001)$ increase in plasma nitrite anions relative to the control group of animals by an average of 43.81 and $34 \%$, respectively, on the 10 th, 20th and 30th day (Fig. 1). On the 50th and 60th day of observation, the content of nitrite anions in the blood plasma of experimental animals, on the contrary, decreased ( $p \leq 0.002)$ by 31 and $26 \%$ (Fig. 2 ).

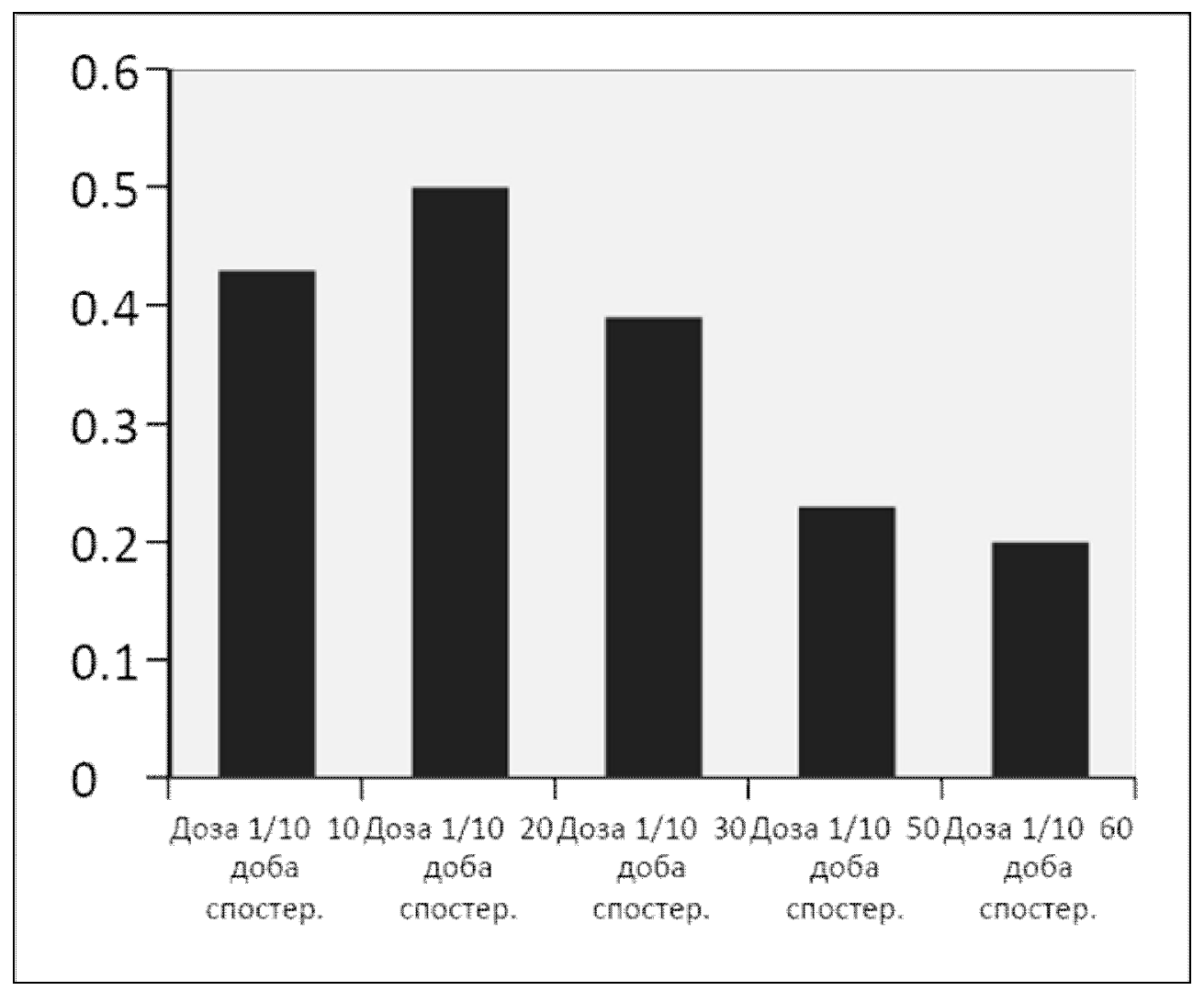

Fig. 1. The content of nitrite anions in the blood plasma of rats under the action of sodium fluoride in subtoxic doses $(n=10 ; \mathrm{Me}$ [25\%; $75 \%]$ or $M \pm s)$ 


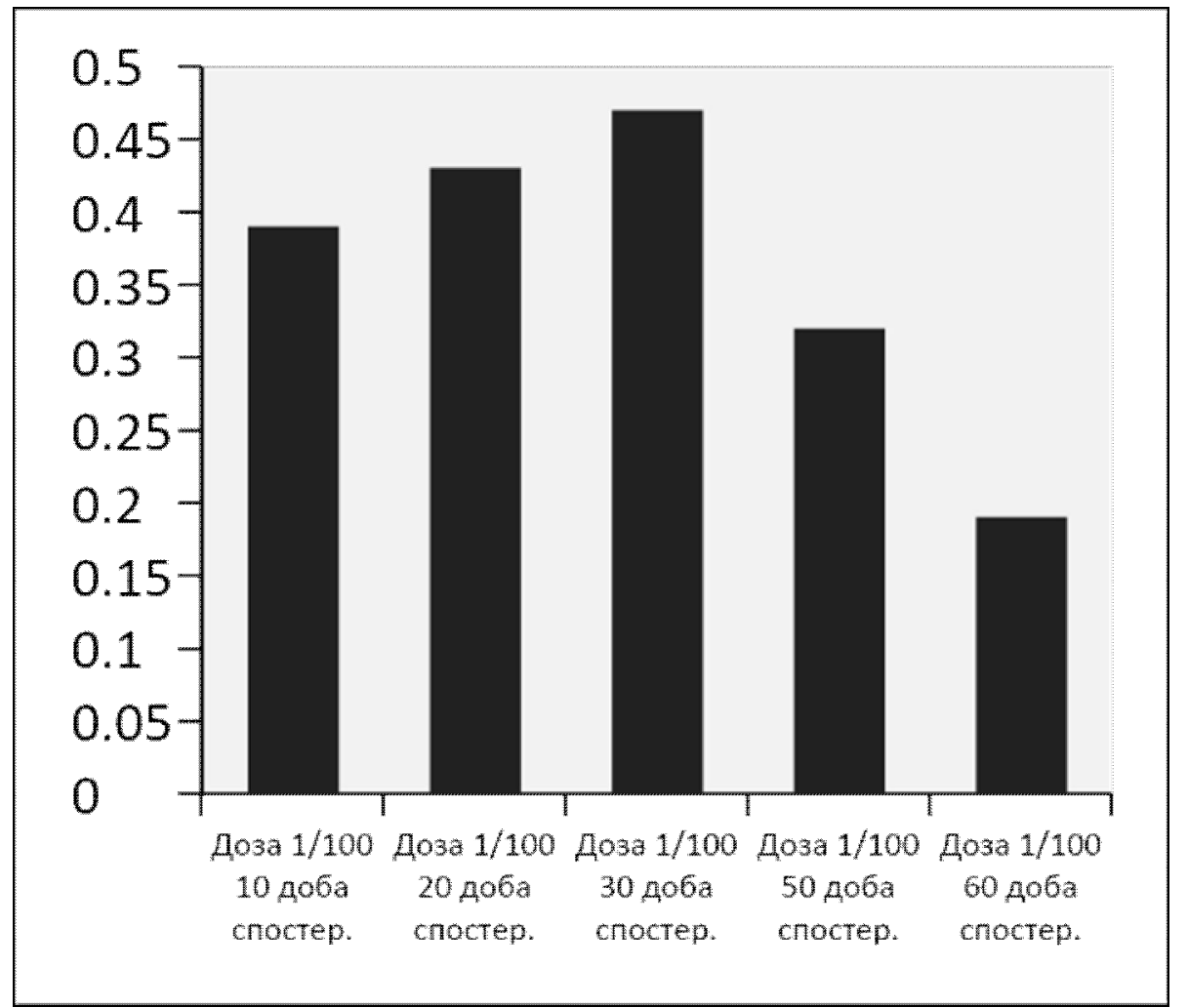

Fig. 2. The content of nitrite and nitrate anions in the blood plasma of rats under the action of sodium fluoride in subtoxic doses $(n=10$; Me [25\%; $75 \%]$ or $M \pm s)$

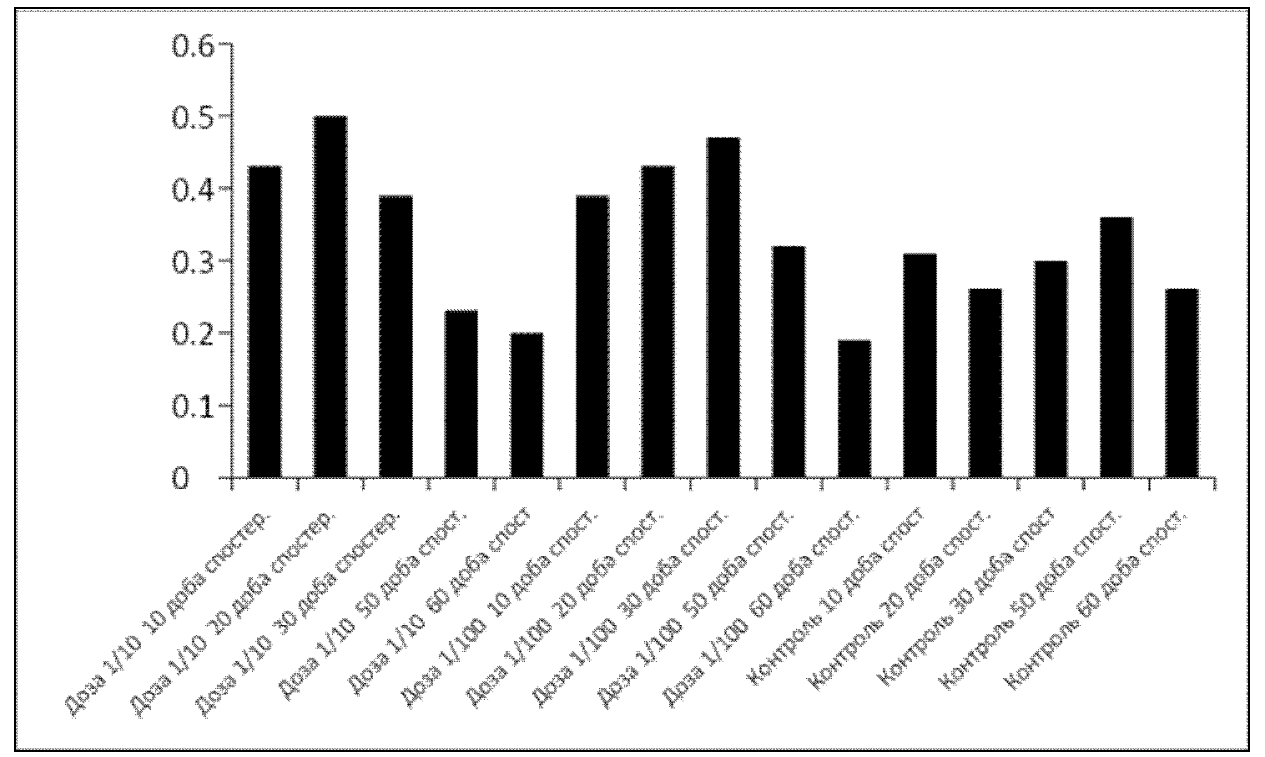

Fig. 3. Dynamics of changes in the content of nitrite anions (in \% relative to control) in the blood plasma of rats during poisoning with sodium fluoride in doses of 1/10 and 1/100 DL50

Note: the content in the control group of animals is taken as $100 \%$

Administration of $\mathrm{FN}$ to animals at a dose of $1 / 100$ DL50 also led to a statistically significant $(p<0.001)$ increase in the content of plasma nitrite anions on the 10th, 20th and 30th day of the experiment by 32,59 and $61 \%$, respectively. On the 50th day, the level of nitrite anions approached the level of animals in the control group $(p=$ $0.162)$, and on the 60th day, it decreased $(p=0.001)$ by an average of $30 \%$.

The results showed a statistically significant $(p$ $<0.001$ ), in relation to the control group of animals, increase in the concentration of nitrate anions in the blood plasma of rats injected with $\mathrm{FN}$ at a dose of 1/100 DL50, on the 10th, 20th, 30th and 50th day, respectively, by 45 , 79,71 and $34 \%$. On the 60th day of observation, the level of nitrate anions did not differ from the control one $(p=0.186)$.

The effect of FN at a dose of 1/100 DL50 was accompanied by a gradual increase as compared to the control of nitrate anions in the blood plasma of the experimental group of rats: on the 10th day - by an average of $22 \%(p=0.003)$, on the 20th day - by $39 \%(p=$ $0.001)$, and on the 30 th day - by $41 \%(p<0.001)$. On the 
50th day of observation, there was also an increase in $=0.089)$, while on the 60th day, on the contrary, there the level of nitrate anions by $13 \%$, but it was unreliable ( $p$ was a reliable $(p=0.011)$ decrease of $17 \%$ (Fig. 4$)$.

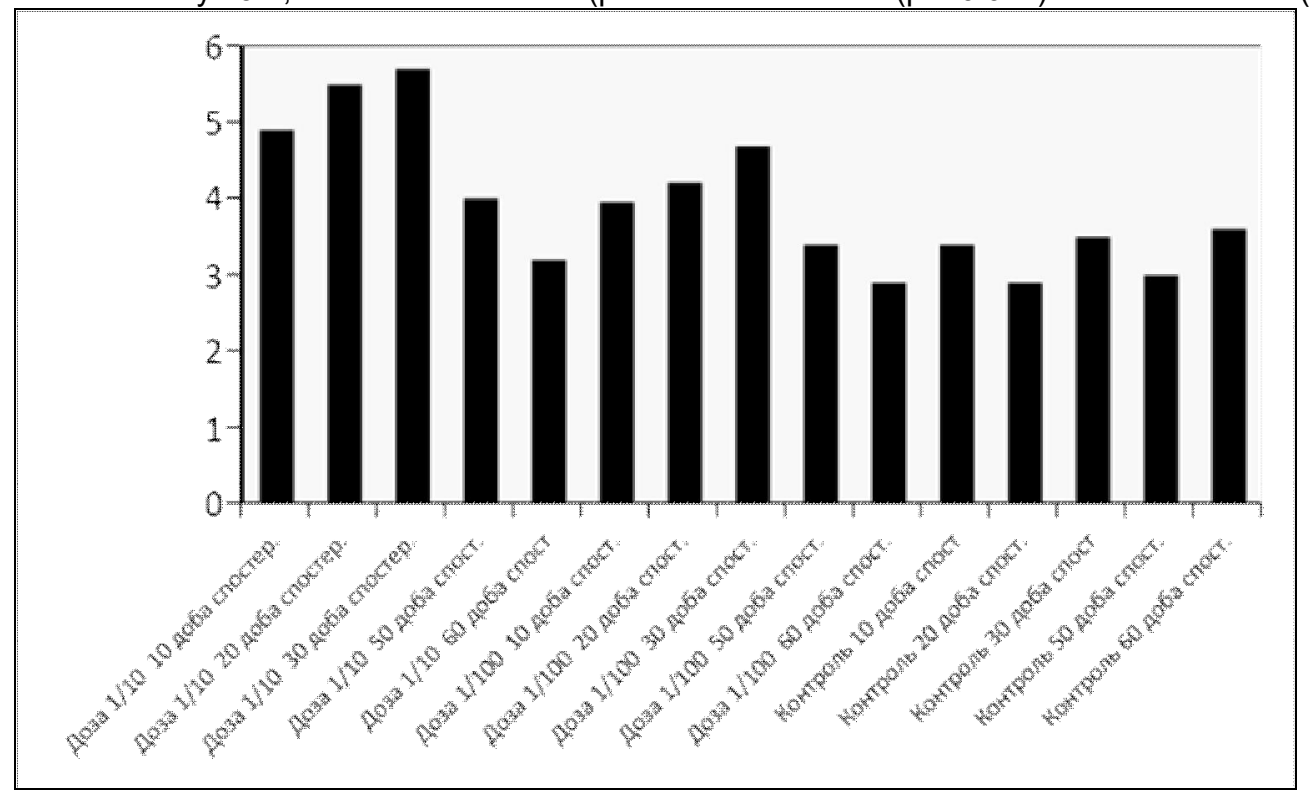

Fig. 4. Dynamics of changes in the content of nitrate anions (in\% relative to control) in the blood plasma of rats during poisoning with sodium fluoride in doses of $1 / 10$ and $1 / 100$ DL50

Note: the content in the control group of animals is taken as $100 \%$

Thus, the detected increase in the plasma of rats of nitrite and nitrate anions under the action of FN in doses of $1 / 10$ and $1 / 100$ DL50 indirectly indicates excess production of $\mathrm{NO}$, which in the initial stages of intoxication may play a compensatory role, but later transformed into pathological reaction with activation of oxidative stress. Typically, excess levels of terminal stable NO metabolites are associated with overexpression of the inducible isoform of NO synthase (iNOS) resulting from oxidative stress. iNOS produces NO in an amount that is several orders of magnitude higher than the production of NO by the endothelial isoform of NO synthase and causes the stimulation of the formation of free radicals [7]. As a result, a larger amount of $\mathrm{NO}$ is formed, which is confirmed by an increase in the content of its final products.

The detected decrease in nitrite and nitrate anions at the end of long-term action of FN indirectly indicates a decrease in NO generation, which may be due to a number of reasons, such as inhibition of NO synthase activity, increased peroxynitrite concentration due to NO use in reaction with superoxide anion -radical, deficiency of enzymes of the antioxidant system, reduction of the precursor of the synthesis of NO-arginine or the main cofactor of NO-synthase - tetrahydrobiopterin, etc. [8].

\section{Conclusions}

Oral administration of $\mathrm{FN}$ to rats in doses of $1 / 10$ and $1 / 100$ DL50 leads to an increase in the content of nitrite and nitrate anions in the blood plasma during the first 30 days, which indirectly indicates excess production of nitric oxide, which in the initial stages of intoxication can perform the compensatory role, but subsequently causes pathological reactions associated with the activation of oxidative stress. The decrease in nitrite and nitrate anions at the end of long-term action of FN indirectly indicates a decrease in nitric oxide generation, which may be associated, in particular, with an increase in peroxynitrite concentration due to the use of nitric oxide in reaction with superoxide anion radical and antioxidant deficiency.

\section{References}

1. Alekhina DA, Zhukova AG, Sazontova TG. Low dose of fluoride influences to free radical oxidation and intracellular protective systems in heart, lung and liver. Technologies of living systems. 2016; 13(6): 4956.

2. Kazarina LN, Samarkina AN, Pursanova AE. Medical aspects of complex prophylaxis and treatment of fluorosis in the case of children living in ende mic district. Medical almanac. 2015; (3): 172175.

3. Zhukova AG, Mikhailova NN, Yadykina TK, Alekhina DA, Gorokhova LG, Romanenko DV et al. Experimental studies of intracellular liver protective mec hanisms in development of chronic fluorine intoxication. Occupational medicine and industrial ecology. 2016; (5): 2124

4. Akimov OY, Mischenko AV, Kostenko VO. Influence of combined nitrate and fluoride intoxication on connective tissue disorders in rats gastric mucosa. Archives of the Balkan Medical Union. 2019; 54(3):11-15. doi: 10.31688/ABMU.2019.54.3.03

5. Yelins'ka AM, Akimov OY, Kostenko VO. Role of AP-1 transcriptional factor in development of oxidative and nitrosative stress in periodontal tissues during systemic inflammatory response. Ukrainian Biochemical Journal. 2019; $\quad$ 91(1):80-85.

https://doi.org/10.15407/ubj91.01.080

6. Akimov OYe, Kovalova IO, Kostenko VO. Correction of destructive changes in connective tissues of different organs during chronic nitrate and fluoride intoxication by nanosized silica oxide. Journal of Education, Health and
Sport. 2019 9(5):547-555.

http://dx.doi.org/10.5281/zenodo.3238594.

7. Akimov OYe, Mishchenko AV, Kostenko VO. Correction of oxidative stress in gastric mucosa of rats by enterosorbents of different classesduring chronic nitrate fluoride intoxication. Aktual'ni problemy suchasnoyi medytsyny: Visnyk Ukrayins'koyi medychnoyi stomatolohichnoyi akademiyi. 2019; 19(2):103-106. doi 10.31718/20771096.19.2.103.

8. Akimov OYe, Kostenko VO. Superoxide and peroxynitrite production in gastric mucosa of rats under combined nitrate-fluoride intoxication. Journal of the Grodno State Medical University. 2018; 16(6):730-734. doi: 10.25298/2221-8785-2018-16-6-730-734

Матеріал надійшов до редакції 02.11.2020 